\title{
APLICATIVOS AUTÓCTONES EM FRANQUIAS JORNALÍSTICAS: ESTRATÉGIAS E TRANSFORMAÇÕES A PARTIR DA CONVERGÊNCIA COM MEIOS DIGITAIS
}

\author{
Autochthonous apps in franchise newspaper: strategies and transformations \\ from convergence with digital media
}

Aplicaciones autóctonas en franquicias de periodismo: estrategias y transformaciones desde la convergencia con medios digitales

\begin{abstract}
Vivian de Carvalho Belochio Coordenadora do Programa de Pós-Graduação em Comunicação e Indústria Criativa da Universidade Federal do Pampa vicabel@terra.com.br
\end{abstract}

Eugenia Maria Mariano da Rocha Barichello Professora do Programa de Pós-Graduação em Comunicação da Universidade Federal de Santa Maria. eugeniabarichello@gmail.com

Tanise Arruda Acadêmica de Jornalismo da Universidade Federal de Santa Maria tanise_mat@yahoo.com.br

\section{Resumo}

Este texto relata pesquisa sobre as características das estratégias em mídias móveis de franquias jornalísticas vinculadas a jornais de referência brasileiros. O foco é a movimentação dessas franquias em aplicativos autóctones, com conteúdos exclusivos, a partir da convergência com meios digitais. $\mathrm{O}$ artigo expõe os resultados de pesquisa que averiguou as movimentações de 25 franquias jornalísticas brasileiras de meios impressos que realizam estratégias de distribuição de conteúdos na Web e em aplicativos móveis. A análise dos dados permite concluir que as movimentações das franquias observadas em seus aplicativos de tablets são conservadoras. A maioria delas apresenta apenas transposição de conteúdos de webjornais e a versão flip de suas publicações. Apenas quatro disponibilizam, nos apps, produtos diferenciados, multimídia, interativos e com conteúdos adaptados. Diante disso, consideramos que os aplicativos autóctones não parecem ser a opção adotada atualmente pelos veículos jornalísticos aqui pesquisados.

Palavras-chave: Convergência. Franquias jornalísticas. Aplicativos autóctones. 


\begin{abstract}
This paper describes research about the characteristics of the strategies in mobile media of newspaper franchises linked to reference Brazilian newspapers. The focus is the movement of these franchises in autochthonous applications, with exclusive content from the convergence with digital media. The article presents the results of research that examined the movement of 25 Brazilian newspaper franchises of print media that perform content distribution strategies in web and mobile applications. The analysis of the data allows to conclude that the franchise moves observed in your tablet apps are conservative. Most of them present only transposition of content from web newspapers and the flip version of their publications. Only four in the apps offer differentiated, multimedia, interactive and adapted content. In view of this, we consider that the autochthonous applications do not seem to be the option currently adopted by the journalistic vehicles studied here.
\end{abstract}

Key words: Convergence. Newspaper franchises. Autochthonous apps.

\title{
Resumen
}

Este artículo describe la investigación de las características de las estrategias en las franquicias de periodismo de los medios móviles vinculados a periodicos de referencia brasileños. El enfoque es el movimiento de estas franquicias en aplicaciones autóctonas, con contenido exclusivo, a partir de la convergencia con medios digitales. El artículo presenta los resultados de las investigaciones que examinaron el movimiento de 25 franquicias de periódicos brasileños impresos que realizan estrategias de distribución de contenidos en web y en aplicaciones móviles. El análisis de los datos permite concluir que los movimientos de las franquicias observadas en sus aplicaciones de tabletas son conservadoras. La mayoría de ellas sólo presentan transposición de contenidos de webjornales y la versión flip de sus publicaciones. Sólo cuatro ofrecen, en las aplicaciones, productos diferenciados, multimedia, interactivos y con contenidos adaptados. Por lo tanto, consideramos que las aplicaciones autóctonas no parecen ser la opción adoptada actualmente por los vehículos periodísticos aquí investigados.

Palabras clave - Convergencia. Franquicias de periodismo. Aplicaciones autóctonas.

\section{Introdução}

Este trabalho expõe resultados de investigação sobre as características das estratégias em mídias móveis de franquias jornalísticas vinculadas a jornais de referência ${ }^{1}$ brasileiros. $\mathrm{O}$ surgimento de publicações que levam a mesma marca de veículos noticiosos tradicionalmente reconhecidos por sua atuação em apenas um suporte é a característica central da formação dessas franquias (DIAS SOUZA; MIELNICZUK, 2009; ZAGO; BELOCHIO, 2014;

\footnotetext{
${ }^{1}$ De acordo com Kuschik Berger (1996, p.1), “o jornal de referência pretende testemunhar o mundo, produzindo um discurso universal e objetivável”. Ele é vinculado à chamada imprensa tradicional, ou seja, tem ligação com a mídia que conquistou credibilidade e reconhecimento do público no decorrer da sua história, mantendo certo padrão na sua postura e no seu discurso, bem como no formato dos seus produtos. Neste trabalho, utilizamos o termo mídias de referência seguindo a linha de pensamento da autora.
} 
BELOCHIO; ZAGO, 2014). Experiência relevante nesse sentido é a criação de webjornais com a mesma identidade editorial de determinados meios. Veículos jornalísticos como o gaúcho Zero Hora, o paulista Estadão e o espanhol El País realizam a estratégia. Recentemente, aparatos móveis como smartphones e tablets foram incluídos nessas movimentações. Surgiram aplicativos que funcionam como publicações noticiosas nos referidos suportes.

Acredita-se que tal ação gera demandas distintas e pode implicar em alterações significativas na forma de pensar o fazer jornalístico em redações que aderem a esse tipo de produção. Isso porque os aplicativos jornalísticos seguem lógicas peculiares, têm estrutura visual específica e design jornalístico ${ }^{2}$ próprio. Visam à produção direcionada às características e necessidades do suporte, das tecnologias e das interfaces utilizadas. Não comportam, portanto, apenas a replicação de dados dos suportes mais antigos, ou tímidas adaptações. Exigem atenção particular às suas singularidades. Esse tipo de app é definido por Barbosa (2013)como autóctone, criado exclusivamente para a disponibilização de notícias em tablets. Marca o desenvolvimento da quinta geração ${ }^{3}$ do jornalismo em redes digitais ${ }^{4}$.

Entende-se que as adaptações das franquias jornalísticas às demandas da produção para aplicativos autóctones podem afetar desde a estruturação dos produtos mantidos pelas organizações até os seus sistemas de apuração, composição e circulação das notícias, entre outros. Isso tendo em vista a ideia de que, nas redações jornalísticas multiplataforma, "já não se tem uma oposição entre meios antigos/tradicionais e os new media" (BARBOSA, 2013, p.34). Tal aspecto marca a complexificação das rotinas produtivas e dos produtos jornalísticos, bem como a possibilidade de modificação dos mesmos. Visto isso, é relevante a observação do fenômeno, com a finalidade de identificar e compreender os seus elementos e as suas implicações no jornalismo contemporâneo. A intenção, aqui, é verificar aspectos das

\footnotetext{
2 O design emite informação sobre o material diagramado e acerca da identidade de quem distribuiu os elementos no espaço (PEREIRA JÚNIOR, 2006). O design jornalístico é considerado potencializador do discurso noticioso impresso, tornando-o competitivo na era da comunicação digital (FREIRE, 2009).

${ }^{3}$ Segundo Mielniczuk (2003), a primeira geração é marcada pela transposição dos conteúdos e padrões dos jornais impressos para a Web; a segunda geração já demonstra algumas adaptações a esse meio, como o uso de hiperlinks; a terceira geração tem como marca central o início da produção mais focada nas particularidades da Web e nas suas possibilidades para as narrativas e para a interação. Barbosa (2007) define a quarta geração do jornalismo digital como a fase de adoção do jornalismo digital em base de dados como paradigma.

${ }^{4}$ Entende-se que a diversidade de suportes e interfaces disponíveis na atualidade tornam o jornalismo em redes mais abrangente e complexo que o webjornalismo, definido como o jornalismo na Web (MIELNICZUK, 2003). Assim, em concordância com Barbosa (2007) e Souza (2008), optou-se, neste trabalho, pela utilização do termo jornalismo em redes digitais, que envolve o uso de tecnologias, suportes e interfaces diferenciadas, que podem ser acessadas através do ciberespaço (LEMOS, 2004; 2005 2006).
} 
ações desenvolvidas em mídias móveis pelas franquias jornalísticas, percebendo, assim, transformações possíveis nas suas estratégias em redes digitais.

Para refletir sobre as questões expostas, este artigo discute, inicialmente, as estratégias de distribuição multiplataforma em contextos de convergência jornalística (DOMINGO et al, 2007; SALAVERRÍA; NEGREDO, 2008). Relaciona tais ações com a convergência com meios digitais (BELOCHIO, 2012) e a utilização de mídias móveis em tais processos. Na sequência, destaca aspectos relacionados à formação de franquias jornalísticas no cenário da cultura da convergência (JENKINS, 2008; DIAS SOUZA; MIELNICZUK, 2009; DIAS SOUZA, 2011; ZAGO; BELOCHIO, 2014; BELOCHIO; ZAGO, 2014). Analisa as mudanças possíveis no jornalismo a partir da inclusão de aplicativos autóctones (BARBOSA, 2013) nas suas estratégias. Por fim, são descritos os resultados da observação das movimentações de 25 franquias jornalísticas brasileiras de meios impressos que realizam estratégias de distribuição de conteúdos na Web e em aplicativos móveis.

\section{Estratégias multiplataforma na convergência com meios digitais}

O investimento em estratégias multiplataforma no jornalismo não é prática nova. Acontece desde que as organizações noticiosas começaram a trabalhar com mais de uma mídia em suas produções. Isso vem resultando na necessidade de adaptação dos jornalistas e dos produtos jornalísticos disponibilizados aos públicos. Salaverría e Negredo (2008) chamam a atenção para o fato de que a acumulação de tarefas nas redações, ou a polivalência dos profissionais, não é recente. Eles lembram que ela sucede há pelo menos meio século, período no qual os repórteres se transformaram em redatores. Empresas que trabalham com impresso e rádio são exemplos, já que organizações com esse perfil vêm investindo há décadas em sistemas de produção das notícias para distintos suportes.

O que se percebe atualmente é a potencialização desse tipo de ação, que ocorre a partir das possibilidades das tecnologias digitais (DOMINGO et al, 2007; SALAVERRÍA; NEGREDO, 2008; BARBOSA, 2009; RODRIGUES, 2009; RAMOS, 2011; PAVLIK; McINTOSH, 2011). Os aparatos úteis à produção e à distribuição de conteúdos são cada vez mais miniaturizados e acessíveis (LEMOS, 2004; 2005; 2006). Transformaram-se em computadores coletivos móveis, como observa Lemos (2004). As facilidades da Web 2.0 também contribuem nesse processo (O’REYLLI, 2005; PRIMO, 2006; ROMANÍ; KUKLINSKI, 2008). 
Esses e outros elementos modificam as expectativas e preferências dos públicos que buscam informações, interferindo nas estratégias das empresas jornalísticas, entre outras. Como afirmam Salaverría e Negredo (2008), até pouco tempo atrás, a imprensa, o rádio e a televisão tinham papéis bem definidos no mercado da informação. Ao primeiro correspondia a interpretação, ao segundo a imediaticidade e ao terceiro o entretenimento. Para os autores, no atual ecossistema midiático ${ }^{5}$, com a Internet sendo apropriada para a oferta e o consumo dos três elementos mencionados, entre outros, essa divisão já não é tão evidente. Mistura-se o convencional com novos elementos, o que complexifica a produção e a distribuição de notícias.

Se a Internet provocou tamanha transformação, o surgimento dos aparatos móveis intensificou ainda mais esse processo. Após a adaptação das empresas às especificidades do webjornalismo (BARDOEL; DEUZE, 2001; ALVES, 2001; FERRARI, 2004; PALACIOS, 2002; BARBOSA, 2002; RIBAS, 2005; SALAVERRÍA, 2005; MIELNICZUK, 2003), os jornalistas precisam lidar mais uma vez com demandas de adequação (BARBOSA, 2012; SILVA, 2008; 2012; PALACIOS, 2012; BARBOSA et al, 2013; PALACIOS et al, 2014). Elas surgem com o investimento em publicações para suportes móveis.

Para Silva (2013), a apropriação das mídias móveis no jornalismo resulta na reconfiguração de dinâmicas de produção, de distribuição e de acesso às notícias. Novas práticas podem surgir nas estratégias que se concretizam através desses aparatos. Segundo Belochio (2012) a produção multiplataforma, que inclui tais aparatos, parte da convergência com meios digitais ${ }^{6}$ é uma dessas práticas. Domingo et al $(2007$, p.10) ressaltam que a estratégia se tornou mais comum a partir da "maturidade da Internet e das comunicações móveis $7 "$. Os autores observam que, juntamente com o desenvolvimento da TV digital, o investimento nesse tipo de produção permite a ampliação das opções para que os públicos acessem as notícias.

Trata-se de uma das transformações visualizadas a partir da intensificação dos processos de convergência jornalística. Estes envolvem, entre outras movimentações, a implantação de diferentes sistemas de produção e de distribuição das informações em redações unificadas. As referidas mudanças são características desse tipo de convergência e se

\footnotetext{
${ }^{5}$ Este ecossistema mistura, atualmente, a atuação dos três meios clássicos em redes digitais, conforme Salaverría e Negredo (2008). Assim, complexifica os sistemas de composição e circulação das notícias, bem como os seus processos de recepção.

${ }^{6}$ A convergência com meios digitais será melhor definida no decorrer deste artigo.

${ }^{7}$ Tradução livre do seguinte trecho: "The maturity of the Internet and mobile communications" (DOMINGO et al, 2008, p.10).
} 
tornaram mais fortes e frequentes a partir da apropriação das tecnologias digitais (AVILÉS, 2006; DOMINGO et al, 2007; SALAVERRÍA; NEGREDO, 2008; BARBOSA, 2009; RODRIGUES, 2009; RAMOS, 2010; PAVLIK; McINTOSH, 2011).

$\mathrm{Na}$ realidade descrita até aqui, são ampliadas as demandas pela produção de pautas integradas nas redações (SALAVERRÍA; NEGREDO, 2008). Elas implicam em pensar a cobertura e a constituição das matérias para mais de um suporte, como impresso, TV e Web. Tal processo vem sendo transformado na convergência com meios digitais, como afirma Belochio (2012), processo entendido como um dos movimentos possíveis em contextos de convergência jornalística.

Em pesquisa anterior (AUTORA), percebeu-se que as mídias móveis não são consideradas como elementos da chamada escala midiática, proposta por Salaverría e Negredo (2008). Esta prevê possibilidades de produção integrada em meios jornalísticos que trabalham com várias mídias. Salaverría e Negredo (2008) elaboraram tal escala definindo modelos de convergência a dois, a três e a quatro, sempre relacionando suas possibilidades à combinação da produção para a Web com mídias tradicionais, como o impresso, a TV e o rádio. No primeiro nível, ocorre a produção integrada para impresso e Web. No segundo nível, são utilizados impresso, TV e Web. No último nível, as estratégias multiplataforma envolvem impresso, TV, rádio e $W e b$.

A convergência com meios digitais vai além da referida escala. Modifica e amplia as movimentações citadas. Isso à medida que envolve a criação de representações dos veículos jornalísticos exclusivamente em redes digitais, incluindo as mídias móveis nas suas estratégias (AUTORA). São exemplos webjornais e aplicativos autóctones (BARBOSA, 2013), definidos anteriormente. Interessam, neste trabalho, as franquias jornalísticas que realizam essa última estratégia.

\section{Cultura da convergência e franquias jornalísticas}

Os fatores expostos podem ser associados à realidade da cultura da convergência, descrita por Jenkins $(2008$, p. 27) como um fenômeno marcado pela interação entre "novas e antigas mídias (...) de formas cada vez mais complexas”. Ele destaca que neste modelo acontecem o "fluxo de conteúdos através de múltiplos suportes midiáticos", a "cooperação entre múltiplos mercados midiáticos" e o "comportamento migratório dos públicos dos meios 
de comunicação". Estes públicos vão buscar as experiências de entretenimento que desejam em qualquer lugar.

Trata-se de uma conjuntura marcada pela transformação do ecossistema midiático (BARICHELLO et al, 2013). No referido cenário, os meios de comunicação hibridizam-se e desenvolvem-se coexistindo em redes digitais, de forma distinta dos processos da comunicação de massa. "A lógica de circulação de informações se transforma, deixando de ser centralizada nas tradicionais instituições de mediação" (CARVALHO; BARICHELLO, 2013, p.68). Em outras palavras, não são apenas os conglomerados midiáticos que têm o privilégio de produzir, publicar e distribuir conteúdos em nível global. Qualquer cidadão ou organização pode realizar tais ações, muitas vezes competindo pela escolha dos públicos. Logo, os processos de midiatização (FAUSTO NETO, 2007) são potencializados no atual ecossistema midiático.

Portanto, nesse ecossistema midiático, as preferências dos consumidores se mostram alteradas com relação a épocas anteriores. Modifica-se o relacionamento estabelecido pelo público com as mídias tradicionais, tais como os veículos noticiosos. Uma vez que este possui mais opções para conseguir as informações que deseja, ou mesmo para obter o entretenimento que procura, acaba se tornando mais exigente (BELOCHIO, 2012). Transformam-se as suas expectativas com relação ao perfil dos produtos disponibilizados pelas organizações de comunicação midiática. Tal alteração demonstra a tendência de que as trocas planejadas e realizadas nesse cenário sejam diferentes. Como os cidadãos esperam por padrões distintos das organizações midiáticas, não é possível que elas continuem apostando em táticas convencionais para conquistar a sua atenção.

Assim, surgem configurações como as franquias nos veículos noticiosos que pretendem se adequar às demandas da cultura da convergência. O termo franquias é utilizado por Jenkins (2008) para descrever estratégias de determinadas marcas que podem resultar na narrativa transmidiática. Esta é marcada pela disponibilização de histórias que podem ser contadas por meio de distintos suportes midiáticos. Isso ocorre de maneira adicional ou complementar, sem replicações e sobreposições (JENKINS, 2008).

As representações pertencentes às franquias jornalísticas integram a cadeia de distribuição multiplataforma de veículos noticiosos no cenário da cultura da convergência ${ }^{8}$

\footnotetext{
${ }^{8} \mathrm{O}$ cenário da cultura da convergência é marcado, entre outros aspectos, pela alteração do comportamento dos públicos na busca e acesso às informações. A variedade de plataformas que disponibilizam notícias e conteúdos diversos, bem como a naturalização, pelos cidadãos comuns, da possibilidade de produzir, publicar e distribuir
} 
(JENKINS, 2008). Podem possibilitar o que Dias Souza (2011) entende como lógica transmídia. Ela ocorre quando os meios noticiosos procuram atender demandas dos públicos em distintas plataformas, contando suas histórias de forma diferenciada e adaptada em cada espaço. É associada “à fragmentação, à dispersão e à expansão" de conteúdos (DIAS SOUZA, 2011, p.61) em diferentes mídias.

Renó e Renó (2013) acreditam que a narrativa transmidiática implica em práticas que vão além das ações convencionais no jornalismo. Visto isso, os jornalistas precisam se adaptar para pensar suas produções de maneira adequada nos movimentos de distribuição multiplataforma. Os autores consideram que a replicação de conteúdos e a repetição de estratégias dos meios mais antigos não são as táticas mais adequadas nesses casos.

$\mathrm{Na}$ convergência com meios digitais, as franquias jornalísticas têm apresentado esse tipo de estratégia. Produzem conteúdos diferentes, propondo narrativas que se complementam, apoiando-se em seus produtos na Web e, em alguns casos, em mídias móveis. Como o foco deste trabalho é essa última situação, os aplicativos jornalísticos para mídias móveis serão melhor definidos na sequência.

\subsection{Aplicativos autóctones de franquias jornalísticas: novas demandas de produção}

Segundo Barbosa (2013, p.43), os aplicativos autóctones são “originalmente desenhados, criados, editados por equipes específicas, segundo affordances, isto é, propriedades, a exemplo da tactilidade (...), atributos do design para tablets (...), e com o emprego de recursos diferenciais para a composição de conteúdos". Entende-se que eles assumem o papel de publicações noticiosas projetadas e construídas com base nas peculiaridades dos suportes móveis. Como mídias distintas das mais antigas, os aplicativos exigem estratégias exclusivas. À medida que apresentam diferentes demandas às equipes editoriais, podem modificar as maneiras como são produzidas e apresentadas as notícias.

Esse tipo de publicação é classificado como produto da quinta geração do jornalismo em redes digitais, que é caracterizada, conforme Barbosa (2013, p.46), pela formação de um "continuum multimídia de cariz dinâmico". Trata-se de um contexto no qual a produção e a distribuição de notícias segue lógicas da convergência jornalística, sendo multiplataforma.

informações, ampliam as suas opções. Tais ações são potencializadas pelas tecnologias digitais e pelo ciberespaço (JENKINS, 2001; 2008). Assim, mudam as expectativas dos públicos com relação ao que podem consumir e compartilhar nesse cenário, obrigando, dessa forma, sistemas tradicionais a se adaptarem. Isso também se aplica ao jornalismo de referência (BELOCHIO, 2012). 
Como destaca Barbosa (2013), nesta fase, o paradigma do Jornalismo em Base de Dados é determinante. A horizontalidade e a medialidade marcam os fluxos de conteúdos entre distintas plataformas. A autora observa que a medialidade (GRUSIN, 2010) marca a produção de diferentes formatos para o jornalismo, como texto, áudio, audiovisual, fotos e infográficos, com o uso das tecnologias digitais e em rede. Ou seja, não há mais produção sem a utilização das mesmas, independente da mídia. Cada fase de constituição das notícias é caracterizada por esses processos, que atualizam os tradicionais. Assim, nas redações multiplataforma em contextos de convergência jornalística ${ }^{9}$, intensifica-se a horizontalidade na produção, edição e distribuição das notícias. Em outras palavras, torna-se equilibrada e padrão a "atuação conjunta, integrada, entre os meios, conformando processos e produtos" (BARBOSA, 2013, p.33). A produção para os aplicativos segue essas lógicas.

Em alguns casos, as publicações móveis mantidas pelas organizações jornalísticas multiplataforma são preenchidas com a transposição de informações dos seus meios mais antigos (BARBOSA et al, 2013). Trata-se do que ocorria na primeira geração do webjornalismo (MIELNICZUK, 2003). Contudo, elementos específicos das plataformas móveis vêm sendo utilizados de forma crescente. Para Barbosa (2013, p.43), isso mostra que a “gramática própria, práticas de produção, dinâmicas de consumo e modelos de negócio específicos" das mídias móveis influenciam a produção para os aplicativos. Nesse sentido, conforme a autora, eles são "paradigmáticos".

Os aplicativos estão adquirindo personalidade própria nessa conjuntura. Diante disso, a organização de publicações jornalísticas com esse formato envolve a compreensão sobre as suas particularidades. Elas partem da apropriação das potencialidades dos suportes móveis para a construção de produtos adequados às suas características. Refletindo sobre as peculiaridades de cada suporte para a produção de notícias, Palacios (2013) observa que tablets e smartphones são aparatos que, por suas características próprias, permitem e criam a necessidade de adaptações. Estas partem da observação de aspectos como a portabilidade e a miniaturização.

Os aspectos citados podem influenciar as estratégias que visam ao atendimento diferenciado das necessidades dos públicos que consomem informações em cada mídia. Fatores como o tamanho e o formato de cada conteúdo precisam ser planejados especialmente

\footnotetext{
${ }^{9}$ A convergência jornalística é marcada pela unificação de redações de distintos meios para a produção de pautas integradas. Esta resulta em estratégias multiplataforma (AVILÉS, 2006; DOMINGO et al, 2007; SALAVERRÍA; NEGREDO, 2008; BARBOSA, 2009; RODRIGUES, 2009; RAMOS, 2010; PAVLIK; McINTOSH, 2011). Esse tipo de movimentação será mais trabalhado no referencial teórico deste artigo.
} 
para os aplicativos. Como constatado em pesquisa anterior ${ }^{10}$ (BELOCHIO, 2012), até mesmo o assunto das informações pode variar com base nas suas especificidades. Logo, em concordância com Barbosa et al (2013, p.20), entende-se que a composição de aplicativos autóctones exige a construção de "enfoque e narrativas diferenciadas dos outros devices, o que, consequentemente, implica formas diferenciadas de pensar, apurar e estruturar as matérias".

Ao tratar do reaparecimento de publicações vespertinas em aplicativos para tablets, Palacios et al (2014, p.44) observam que "o desdobramento do storytelling exige mais do ponto de vista de design, programação e do pensar sobre a narrativa". Na opinião dos autores, isso cria a necessidade de que os jornalistas trabalhem mais próximos dos designers, por exemplo. Eles também apontam como fundamental "o desenvolvimento de habilidades de compreensão dos recursos propiciados para a edição de conteúdos em aplicativos móveis visando à produção de conteúdo com narrativas diferenciadas/inovadoras".

Tendo em vista as potencialidades e desafios listados, o trabalho com os aplicativos autóctones em franquias jornalísticas pode envolver uma série de adequações. Fica latente que o preenchimento das publicações jornalísticas em mídias móveis não pode seguir o mesmo padrão existente em meios mais antigos, como jornal e webjornal. Sendo assim, a mobilização das redações em busca dessas adaptações exige aprimorar as habilidades dos jornalistas especialmente para a realização de movimentações multiplataforma.

Ao mesmo tempo em que os jornalistas atuam em contextos em que não há mais delimitações diretas sobre a produção para distintas mídias, como visto a partir de Barbosa (2013), precisam desenvolver o pensamento estratégico a respeito dos conteúdos mais adequados para cada plataforma (AGUADO; CASTELLET, 2013; BARBOSA, 2013; OLIVEIRA, 2013; PALACIOS, 2013; PALACIOS et al, 2014). Como definir modelos diferenciados em situações de mistura dos padrões de mídias clássicas e mais recentes? Nas franquias jornalísticas, os profissionais realizam esse tipo de adequação para veículos que mantêm a mesma marca em várias plataformas. Como essa situação interfere nas iniciativas e produtos construídos? Será que estão se intensificando os projetos de produtos diferenciados

\footnotetext{
${ }^{10}$ Em pesquisa doutoral (BELOCHIO, 2012) constatou-se, com base na verificação das manchetes de 18 edições do jornal impresso gaúcho Zero Hora, 18 edições do webjornal Zero Hora.com e 18 edições de Zero Hora no iPad, que os assuntos privilegiados em cada plataforma são diferentes. No período da análise (entre março e abril de 2012), os destaques do jornal impresso em suas manchetes tinham foco principalmente em economia. No webjornal, verificou-se mais destaque aos assuntos da editoria de geral. Já no iPad, percebeu-se ênfase na previsão do tempo nas manchetes. Isso demonstra que os destaques são escolhidos de forma diferenciada para cada mídia mantida pela franquia.
} 
para cada plataforma, ou a convergência com meios digitais ocorre pela repetição de conteúdos? Considerando a premissa de que tais circunstâncias precisam ser compreendidas por jornalistas e por futuros profissionais da área, visto que podem acabar integrando as suas rotinas, o presente artigo propõe contribuir com a reflexão sobre as questões expostas.

\section{Estratégias de franquias jornalísticas brasileiras em apps}

Com o objetivo de verificar as franquias formadas a partir da convergência com meios digitais, este artigo direciona a observação empírica aos veículos impressos que realizam esse movimento. Em outras palavras, foram investigados os jornais que conquistaram credibilidade e reconhecimento ao longo do tempo e que passaram a investir na Web e em mídias móveis.

A pesquisa foi realizada de agosto de 2015 até maio de 2016, em três etapas. São elas a) a identificação das publicações dos principais veículos jornalísticos brasileiros de referência que atuam como franquias; b) a verificação de quais franquias trabalham com publicações na Web e em aplicativos móveis através da convergência com meios digitais; c) averiguação de quais possuem aplicativos autóctones e de peculiaridades das suas interfaces e conteúdos.

A etapa da identificação das publicações em redes digitais pertencentes a franquias jornalísticas brasileiras é exploratória. Visa à observação dos veículos jornalísticos impressos de referência no Brasil que possuem representações nas plataformas da Web e de aplicativos de tablets. Ou seja, foram procuradas publicações que integram a mesma franquia em webjornais e aplicativos jornalísticos disponíveis em suportes móveis.

Os jornais que realizam essa estratégia passaram por observação qualitativa indireta. Esta envolve a coleta e a análise de fontes documentais (DELGADO; GUTIERREZ, 1995) e a notificação de constantes e variantes, permitindo a verificação de dados quantitativos e a sua análise qualitativa. Por meio dessa técnica metodológica, foram identificados os meios que trabalham com aplicativos autóctones, considerando-se aspectos como a oferta de conteúdos exclusivos, de interfaces peculiares e de variações das opções de tipos de publicação. Estas podem ser representações da mídia mais antiga na plataforma móvel ou ter novas identidades e propostas editoriais. Esse é o caso de materiais matutinos e vespertinos, por exemplo. São produtos que vão além da representação principal do veículo jornalístico, sendo direcionados 
totalmente para as mídias móveis. Os meios que não apresentam os mesmos conteúdos do jornal impresso e da Web foram identificados nesta etapa, a partir da comparação das informações em destaque nos apps com as disponíveis nos webjornais e nos jornais impressos das franquias analisadas.

A pesquisa dos principais jornais brasileiros foi realizada através do site Guia de Mídia $^{11}$. Este dispõe de uma lista de jornais, além da cidade, do Estado em que são distribuídos e dos seus respectivos endereços na Web. Com base em tal lista, optou-se por coletar os nomes dos principais jornais das capitais brasileiras, com foco naqueles que possuem versões impressas. Foram encontrados 101 jornais impressos com tais características.

Após essa primeira etapa, foram verificados os tipos de convergência jornalística que esses meios realizam. Para isso, usou-se a classificação de Salaverría e Negredo (2008) da escala midiática, descrita anteriormente. Com relação à convergência a dois (C2), encontrou-se 100 veículos jornalísticos impressos que possuem webjornais ${ }^{12}$. Realizam a convergência a três (C3), isto é, a união de impresso, com TV e com a Web, quatro veículos jornalísticos aqui observados ${ }^{13}$. Além desses, foram encontrados 16 jornais ${ }^{14}$ com versão impressa, na Web e com WebTVs. Foram identificados seis casos ${ }^{15}$ de convergência a quatro (C4), ou seja, veículos que possuem representações em meios impressos, radiofônicos, televisivos e na $W e b$.

No que se refere à convergência com meios digitais, isto é, a união do impresso com a Web e com dispositivos móveis (BELOCHIO, 2012), encontrou-se 25 casos. Eles são referentes à utilização de webjornais e de aplicativos de tablets, que são o foco deste trabalho. Todos foram encontrados na App Store, da Apple, após busca no iPad. A tabela que segue mostra como essas franquias disponibilizam informações nos seus apps:

\footnotetext{
${ }^{11}$ Disponível no endereço: www.guiademidia.com.br.

12 Não foram encontrados webjornais que representam meios impressos de Boa Vista/Roraima. Além disso, no Amazônia em Tempo e no Jornal Agora, ambos de Manaus/Amazônia, verificou-se o uso do mesmo site.

${ }^{13}$ Maceió-Alagoas, sendo que a TV é filiada da Rede Globo - Gazeta de Alagoas; Salvador- Bahi, Tribuna da Bahia; João Pessoa- Paraíba, Jornal da Paraíba, sendo a TV pertencente à Rede Paraíba de Comunicação, filiada da Rede Globo; Rio de Janeiro- Rio de Janeiro - Jornal O Globo.

14 Diário do Amapá (AP); Diário do Nordeste, Jornal O Povo, Jornal O Estado, Jornal A Notícia do Ceará (CE); Jornal O Hoje (GO); Jornal O Imparcial (MA); Jornal O Tempo; Jornal Capital de Minas (MG); O Liberal (PA); Jornal Impacto Paraná (PR); Jornal do Comércio, Folha de Pernambuco (PE); Jornal da Cidade (PI); Tribuna do Norte (RN); Folha de São Paulo, Estado de São Paulo (SP).

${ }^{15}$ Gazeta de Alagoas (AL); Diário do Amapá (AP); O Liberal (PA); Folha de Pernambuco (PE); Jornal O Globo (RJ); O Estado de São Paulo (SP).
} 


\begin{tabular}{|c|c|c|c|}
\hline Franquia & $\begin{array}{c}\text { Edição flip disponível } \\
\text { no } A p p\end{array}$ & $\begin{array}{c}\text { Elementos do } \\
\text { webjornal no } A p p\end{array}$ & $\begin{array}{l}\text { Aplicativos } \\
\text { autóctones }\end{array}$ \\
\hline Gazeta de Alagoas & $\mathrm{x}$ & - & - \\
\hline Jornal do Dia & $\mathrm{x}$ & - & - \\
\hline $\begin{array}{l}\text { Jornal do Commercio } \\
\text { (Manaus/Amazonas) }\end{array}$ & $\mathrm{x}$ & - & - \\
\hline Correio da Bahia & $\mathrm{x}$ & $\mathrm{x}$ & - \\
\hline Jornal A Tarde & $\mathrm{x}$ & - & - \\
\hline Correio Braziliense & $\mathrm{x}$ & $\mathrm{x}$ & - \\
\hline Jornal de Brasília & $\mathrm{x}$ & - & - \\
\hline A Tribuna & $\mathrm{x}$ & - & - \\
\hline Diário do Norte & $\mathrm{x}$ & - & - \\
\hline O Estado doMaranhão & $\mathrm{x}$ & - & - \\
\hline Correio do Estado & $\mathrm{X}$ & - & - \\
\hline O Tempo & $\mathrm{x}$ & $\mathrm{x}$ & - \\
\hline O Liberal & $\mathrm{x}$ & - & - \\
\hline Jornal da Paraíba & $\mathrm{x}$ & $\mathrm{x}$ & - \\
\hline Diário de Pernambuco & $\mathrm{x}$ & - & - \\
\hline $\begin{array}{l}\text { Jornal do Commercio } \\
\text { (Recife/Pernambuco) }\end{array}$ & $\mathrm{x}$ & $\mathrm{x}$ & - \\
\hline Jornal O Globo (RJ) & $\mathrm{x}$ & $\mathrm{x}$ & $\mathrm{x}$ \\
\hline Jornal Extra & $\mathrm{x}$ & - & - \\
\hline Tribuna do Norte & $\mathrm{x}$ & $\mathrm{x}$ & - \\
\hline Novo Jornal & $\mathrm{x}$ & - & - \\
\hline Zero Hora (RS) & $\mathrm{x}$ & $\mathrm{x}$ & $\mathrm{x}$ \\
\hline Diário da Amazônia & $\mathrm{x}$ & $\mathrm{x}$ & - \\
\hline $\begin{array}{c}\text { Diário Catarinense } \\
\text { (SC) }\end{array}$ & $\mathrm{x}$ & $\mathrm{X}$ & $\mathrm{x}$ \\
\hline
\end{tabular}


PROGRAMA DE PÓS-GRADUAÇÃO EM COMUNICAÇÃO DA UNIVERSIDADE FEDERAL DE SANTA MARIA

\begin{tabular}{|c|c|c|c|}
\hline Folha de São Paulo & $\mathrm{x}$ & $\mathrm{x}$ & - \\
\hline O Estado de São Paulo & $\mathrm{x}$ & $\mathrm{x}$ & $\mathrm{x}$ \\
\hline TOTAL & $\mathbf{2 5}$ & $\mathbf{1 2}$ & $\mathbf{4}$ \\
\hline
\end{tabular}

Tabela 1 - Tipos de conteúdos e publicações disponibilizadas nos aplicativos móveis observados

Fonte - Autoras.

Como pode ser conferido na 'Tabela 1', percebeu-se três tipos de iniciativas predominantes nos aplicativos observados. São elas: a) a oferta da edição flip dos veículos jornalísticos; b) a disponibilização de conteúdos dos webjornais das franquias nos apps; c) a apresentação de conteúdos exclusivos, característica de aplicativos autóctones. Em determinados casos, apenas um tipo de elemento foi encontrado nas 25 franquias observadas. Cabe observar que elas estão identificadas na coluna da esquerda. Noutros, a mistura dos mesmos foi notificada. Os tópicos em vermelho indicam os casos relacionados aos apps autóctones. Os resultados serão descritos na sequência, com a exposição de exemplos.

Todas as 25 franquias jornalísticas analisadas nesta etapa disponibilizam, em seus aplicativos, a versão flip dos seus jornais diários. Trata-se da edição impressa digitalizada. O fato de a totalidade dos meios pesquisados oferecerem tal edição demonstra que as suas estratégias em tablets podem estar apoiadas nesse tipo de iniciativa, considerada conservadora. Ao todo, 20 veículos do conjunto observado utilizam o PDF simples nessas edições, privando-se de explorar características mais específicas dos tablets.

Vale lembrar que, além dos jornais flip, os apps desse grupo possuem menus fixos básicos, que podem ser tocados para o acesso de outros recursos. Estes são compostos por opções como "minhas edições", “ajuda", "banca" e "fale conosco", por exemplo. Normalmente, localizam-se no cabeçalho ou no rodapé dos aplicativos. Alguns desses meios permitem o compartilhamento dos materiais acessados nos aplicativos via sites de redes sociais, como o Twitter e o Facebook, ou através do e-e-mail. Além disso, dispõem de mecanismos de busca. Outros veículos apresentam recomendações básicas sobre a utilização das ferramentas dos apps.

As 12 franquias classificadas na categoria 'Elementos do webjornal no App' oferecem a versão flip juntamente com recursos da rede, não limitando seus conteúdos ao que é oferecido na Web. Nos casos em que existe a opção de acessar as informações disponíveis nos webjornais das franquias, são acrescentados, nas interfaces, botões como "últimas notícias". 
Estes permitem o acesso dos públicos aos conteúdos publicados nas representações dos veículos jornalísticos na Web. Na maioria dos 12 casos identificados, os navegadores são direcionados às páginas dos jornais na rede, sem que ocorra a seleção prévia dos materiais que poderiam ser mais interessantes aos apps. Em outras palavras, não se trata da cópia de conteúdos de um espaço para o outro. As plataformas móveis e da Web são ligadas através de caminhos hipertextuais.

São exceções o jornal gaúcho ZH, A Tribuna do Norte, de Natal/RN, e o Diário Catarinense. As franquias pertencentes aos veículos citados expõem, nos seus apps, com destaque, apenas alguns conteúdos dos seus webjornais. As informações são distribuídas entre manchetes e chamadas. Estas são exibidas com mais ou menos destaque na capa dos aplicativos. Isso a partir de elementos como o tamanho da fonte, o negrito e a exposição de fotografias. Quando acessadas, as notícias não são exibidas nas páginas dos veículos noticiosos. Elas aparecem nas interfaces dos apps. Apenas alguns elementos, como infográficos e vídeos, levam os navegadores aos sites dos jornais, a partir de hiperlinks colocados nas matérias.

\subsection{Aplicativos autóctones}

As quatro franquias jornalísticas que disponibilizam mais que apenas as mesmas informações das suas publicações impressas e da Web nos seus apps de tablets são os jornais O Globo, ZH, Diário Catarinense e Estado de São Paulo. Trata-se dos veículos classificados na categoria 'Aplicativos autóctones', conforme consta na 'Tabela 1'. É importante esclarecer que todos os quatro veículos que possuem edições com conteúdos exclusivos também oferecem as opções mais convencionais, como a edição flip, acesso aos webjornais a partir de hiperlinks e notícias selecionadas das suas páginas. Contudo, além dessas opções, as franquias investem na constituição de publicações com conteúdos totalmente direcionados à plataforma móvel, não expostos antes nas suas demais representações. Sendo assim, simultaneamente, observa-se o conservadorismo e a inovação nesses casos, o que demonstra que ainda se está buscando um modelo mais adequado para a exploração da plataforma.

O Jornal O Globo é um dos veículos noticiosos que realiza iniciativas em seu app associadas à proposta de publicações autóctones, com base nas definições de Barbosa (2013). No seu aplicativo, o veículo permite o acesso à edição flip do impresso. A publicação, contudo, não é estática, como a maioria das flip observadas neste trabalho. Ela conta com 
recursos que permitem a navegação entre as representações da franquia, tais como hiperlinks e remissões. Estas levam os interagentes ao site de O Globo. Os anúncios são animados e multimídia. Os leitores têm acesso aos cadernos do impresso. Além desses elementos, a franquia oferece, em seu app, publicação em formato de e-book. Esta é descrita pela organização da seguinte forma:

Confira o material publicado nas páginas do Globo reunido em livros sobre temas de importância histórica. Da visita do Papa Francisco ao Brasil às manifestações que tomaram as ruas do país, confira matérias de acervo e conteúdo exclusivo em coletâneas que ajudam a criar uma visão única sobre diferentes assuntos. Assinantes do Globo podem fazer o download dos livros gratuitamente e não assinantes podem comprá-los através das lojas virtuais Amazon, Google Play e iBook Store ${ }^{16}$. (O GLOBO, 2016)

Percebe-se que os $e$-books não são exclusivamente disponibilizados por intermédio do app de O Globo. Entretanto, trata-se de publicações com conteúdos diferenciados que podem ser acessadas no espaço. Logo, são opções distintas dos demais produtos mantidos pela franquia, que podem ser acessadas através do seu aplicativo.

Vale observar que as remissões e os hiperlinks encontrados na versão flip de O Globo parecem buscar a exploração de elementos mais específicos da interface de mídias móveis, a partir da navegação táctil. Desse modo, pode-se compreender que existe um misto de recursos técnicos mais peculiares da ferramenta com conteúdos exclusivos e informações já veiculadas nas demais representações da franquia. Ou seja, o app é um híbrido. Possivelmente, O Globo está fazendo testes no seu app, visto que iniciativas anteriores, como a publicação O Globo a + , traziam conteúdos exclusivos. Contudo, tal produção foi extinta em 2015, dando lugar à proposta de apresentação dos mesmos conteúdos do jornal impresso e do webjornal no aplicativo, juntamente com os e-books.

O aplicativo do jornal gaúcho Zero Hora conta com destaques do webjornal ZH, previsão do tempo que se atualiza automaticamente e atualização contínua de notícias. As manchetes selecionadas para publicação no app vêm do site de $\mathrm{ZH}$, como conferido em 31/03/2016. A opção da edição impressa leva para o novo aplicativo do veículo, ZH Jornal Digital, que apresenta várias edições digitais do jornal: versão flip interativa da edição impressa do dia; ZH Noite; ZH Domingo Digital e cadernos especiais. Assim como O Globo, todas são híbridas. Possuem ícones especiais com remissões e links que levam os públicos

${ }^{16}$ Disponível em: http://oglobo.globo.com/edicoes-digitais/. 
para outros conteúdos, a maioria disponível em ZH.com. Áudios e vídeos são destacados, além de galerias de fotos e infográficos. ZH Noite tem características de publicação autóctone, já que apresenta conteúdos de opinião não divulgados nas outras versões do jornal, com base nos fatos do dia. ZH Domingo Digital também possui alguns conteúdos exclusivos, sobre os fatos de domingo.

A situação do Diário Catarinense é semelhante à de $\mathrm{ZH}$, talvez devido ao fato de fazer parte do Grupo RBS, também integrado por Zero Hora. Seu app traz os destaques do webjornal DC e expõe, na capa, temperatura do dia em local que pode ser selecionado pelo leitor, atualizando-se automaticamente. As matérias em destaque na capa vêm do site do DC, como conferido em 18/05/2016. No entanto, os destaques do app são diferentes dos do site.

A opção da edição impressa leva para outro aplicativo do veículo, o DC Jornal Digital, que apresenta várias edições digitais do jornal: versão flip não estática da edição impressa do dia; edição especial de fim de semana, DC Domingo Digital e cadernos especiais. Tais publicações possuem ícones especiais com remissões e links que levam os públicos para outros conteúdos, a maioria disponível no webjornal do DC. Áudios e vídeos são destacados, além de galerias de fotos e infográficos. O DC Domingo Digital possui alguns conteúdos exclusivos e outros expostos no webjornal. Sendo assim, tem partes autóctones.

Já o aplicativo do jornal Estado de São Paulo permite o download do Estadão Premium e do Estadão Noite. O Estadão Premium é a edição flip do impresso do dia. É disponibilizado às $5 \mathrm{~h}$ aos assinantes. Conta com galerias de fotos, vídeos e outras notícias do site do Estadão. Estas podem ser acessadas por intermédio de links disponíveis nos selos "Na Web”. Foi considerado básico, sem características de autóctone.

O Estadão Noite é gratuito. Traz várias colunas exclusivas de opinião. Possui poucos elementos hipertextuais e multimídia. Tem características de autóctone por ser voltado exclusivamente à plataforma, com conteúdos projetados para isso. Anuncia as notícias do dia seguinte do Estado de S. Paulo, o que tem de destaque na TV Estadão, na Rádio Estadão e no webjornal Estadão. Apenas conteúdos estáticos aparecem nesta parte, sem hiperlinks: somente chamadas e linhas de apoio. Logo, o app do Estadão também pode ser considerado híbrido.

\section{Considerações pontuais}

A análise dos dados permite concluir que as movimentações das franquias observadas neste trabalho em seus aplicativos de tablets são conservadoras. A ampla utilização da versão 
flip dos jornais, que traz os mesmos conteúdos já apresentados no suporte impresso, permite tal entendimento. Aparentemente, trata-se de uma opção mais barata e acessível às organizações noticiosas, que não têm a intenção de investir na construção de conteúdos adequados ao suporte e suas potencialidades. Não parecem existir planejamento e ações voltadas exclusivamente para a plataforma móvel. O que ocorre é a tentativa de obter lucro através dos apps, visto que assinantes têm acesso livre às publicações e os demais precisam comprá-las.

A apresentação do PDF da edição impressa pode estar sendo considerada um elo de identificação das franquias com os públicos, visto que sua matriz midiática é o jornal impresso. Outrossim, aponta para a possibilidade de que as redações compreendem que os seus leitores esperam receber a versão flip nos aplicativos de tablets. Ou seja, é possível que esteja sendo considerada a ideia de que tais aparatos possam, no futuro, substituir o suporte impresso para a circulação de jornais. Sendo assim, salienta-se, novamente, que os movimentos atuais da convergência com meios digitais nas franquias analisadas podem indicar uma fase de testes e adaptações, para posteriores ajustes e investimentos.

Chama atenção o fato de que apenas quatro franquias, entre as 25 averiguadas nesta pesquisa, realizam iniciativas para tentar diferenciar a plataforma móvel das demais utilizadas nas suas estratégias de distribuição multiplataforma. Diante disso, compreende-se que a disposição para a realização de ações nesse sentido, entendidas como mais ousadas, aparentemente ainda não é tendência entre os jornais de referência brasileiros. Os aplicativos autóctones não parecem ser a opção adotada atualmente pelos veículos jornalísticos aqui pesquisados. O que se percebe é o investimento tímido e inicial em iniciativas híbridas, que misturam modelos clássicos com novas propostas editoriais.

Finalmente, destaca-se que parece incipiente o incentivo para que as redações dos veículos jornalísticos investigados realizem a produção exclusiva de conteúdos aos aplicativos de suas franquias. Pesquisas futuras podem apontar os impactos dessas movimentações nos processos produtivos dos profissionais que trabalham com a convergência com meios digitais. Além disso, podem indicar transformações em curso e os motivos pelos quais não há ações mais ambiciosas em apps móveis nos jornais de referência brasileiros.

\section{REFERÊNCIAS}


AGUADO, J. M. La indústria del contenido em la era Post-PC: Horizontes, amenazas y oportunidades. In:CANAVILHAS,João (org). Notícia e Mobilidade. Universidade da Beira do Interior, Portugal: Labcom, 2013.

AVILÉS, J. A. G. Desmistificando la convergencia periodística. In: Chasqui - Revista Latinoamericana de Comunicación. Edição web nº 94, Junho, 2006.

BARBOSA, S. Jornalismo Digital em Base de Dados (JDBD) - Um paradigma para produtos jornalísticos digitais dinâmicos. Tese de Doutorado desenvolvida no Programa de Pós-Graduação em Comunicação e Culturas Contemporâneas da UFBA. Salvador, 2007.

BARBOSA, S. Convergência jornalística em curso: as iniciativas para integração de redações no Brasil. In: RODRIGUES, C. Jornalismo ON-LINE: modos de fazer. Rio de Janeiro: Ed. PUC-Rio: Editora Sulina, 2009.

BARBOSA, S. “Jornalismo convergente e continuum multimídia na quinta geração do jornalismo nas redes digitais”. In: CANAVILHAS, J. Notícias em mobilidade. Jornalismo na era dos dispositivos móveis. Covilhã: UBI, Labcom, 2013.

BARBOSA, S.; SILVA, F. F.; NOGUEIRA, L.; ALMEIDA, Y. A atuação jornalística em plataformas móveis. Estudo sobre os produtos autóctones e a mudança no estatuto do jornalista. Brazilian Journalism Research, v.9, n.2, 2013.

BARDOEL, J.; DEUZE, M. Network Journalism. Converging Competences of Media Professionals and Professionalism. Australian Journalism Review, v. 23, n. 2, p.91-103, 2001.

BARICHELLO, E.; STASIAK, D.; SCHEID; D.; FLORES, A. C.; MACHADO, J.

Estendendo as práticas de Relações Públicas sob a perspectiva teórica da ecologia das mídias. In: BARICHELLO, E. (org). Ecologia da Mídia. Santa Maria, FACOS-UFSM, 2013.

BELOCHIO, V. Jornalismo em contexto de convergência: implicações da distribuição multiplataforma na ampliação dos contratos de comunicação dos dispositivos de Zero Hora. Tese (Doutorado em Comunicação e Informação), UFRGS. Porto Alegre, 2012.

CARVALHO, L.; BARICHELLO, E. Legitimação das organizações midiáticas no ecossistema digital. In: BARICHELLO, E. (org). Ecologia da Mídia. Santa Maria, FACOSUFSM, 2013.

DELGADO, J.; GUTIERREZ, J. Métodos y técnicos cualitativos de investigación en ciencias sociales. Madrid, Editorial Síntesis, 1995.

DIAS SOUZA, M.; MIELNICZUK, L. Aspectos da narrativa transmidiática do jornalismo na Revista Época. Comunicação e Inovação, v.11, n.20, São Caetano do Sul, 2010. 
DIAS SOUZA, M. Jornalismo e cultura da convergência: a narrativa transmídia na cobertura do Cablegate nos sites El País e Guardian. Dissertação de mestrado defendida junto ao PPGCOM da Universidade Federal de Santa Maria (UFSM). Santa Maria, RS, 2011. DOMINGO, D. et al. (2007). Four Dimensions of Journalistic Convergence: A preliminary approach to current media trends at Spain, 2007. Disponível em:

http://journalism.utexas.edu/online-journalism/2007/papers/Domingo.pdf.

FAUSTO NETO, A. A midiatização jornalística do dinheiro apreendido: das fotos furtadas à fita leitora. XVI COMPÓS: Curitiba/PR, 2007.

JENKINS, H. Cultura da convergência. São Paulo: Aleph, 2008.

KOLODZY, Janet. Convergence Journalism. Writing and reporting across the news media. Lanham, Maryland, USA: Rowman \& Littlefield Publishing Group Inc., 2006.

MIELNICZUK, L. Jornalismo na web: Uma Contribuição para o Estudo do Formato da Notícia na Escrita Hipertextual. Tese de Doutorado desenvolvida no Programa de PósGraduação em Comunicação e Culturas Contemporâneas da UFBA. Salvador, 2003.

OLIVEIRA, V. R. Interfaces jornalísticas em tablets: o design digital da informação nos aplicativos móveis. Dissertação de Mestrado. Universidade Federal de Santa Catarina (UFSC). Florianópolis/SC, 2013.

PALACIOS, M. Jornalismo online, informação e memória: apontamentos para debate. In: http://www.facom.ufba.br/jol/pdf/2002_palacios_informacaomemoria.pdf. Acesso em: 12.04.2007.

PALACIOS, M. O mundo no bolso e no contexto da palma da mão. In: BARBOSA, S.; MIELNICZUK, M. (org.). Jornalismo e tecnologias móveis. Covilhã, UBI, Labcom, 2013.

PALACIOS, M.; BARBOSA, S.; FIRMINO, F.; CUNHA, R. Aplicativos jornalísticos vespertinos para tablets. Cartografia do fenômeno ante o desafio de uma produção original e inovadora. Sobre Jornalismo, $\mathrm{Vol} 3, \mathrm{n}^{\circ} 2$ - 2014. In:

http://surlejournalisme.com/rev

PAVLIK, J. V.; McINTOSH, S. Converging Media. Oxford University Press, 2011.

PEREIRA JÚNIOR, Luiz Costa. Guia para a edição jornalística. Petrópolis/RJ, Vozes, 2006.

RAMOS, D. O. Aspectos da convergência de mídias e da produção de conteúdo multimídia no Clarín.com. Líbero, São Paulo, v. 13, n. 25, p. 143-152, jun. de 2010.

RENÓ, D.; RENÓ, L. Linguagens e interfaces para o jornalismo transmídia. In: CANAVILHAS,João (org). Notícia e Mobilidade. Universidade da Beira do Interior, Portugal: Labcom, 2013. 
RIBAS, Beatriz. A Narrativa Webjornalística: um estudo sobre modelos de composição no ciberespaço. Dissertação de Mestrado. Universidade Federal da Bahia, 2005. In: http://www.facom.ufba.br/jol/doc/2005_ribas_dissertacao.zip

\section{SALAVERRÍA, R.; NEGREDO, S. Periodismo integrado: convergencia de medios y reorganización de redacciones. Barcelona: Editorial Sol90 Media, 2008.}

SILVA, F. F. Jornalismo e tecnologias da mobilidade: conceitos e configurações. Anais do II Simpósio Nacional de Pesquisadores em Cibercultura (ABCiber). São Paulo, novembro de 2008.

ZAGO, G.; BELOCHIO, V. Remediação da experiência de consumo de notícias em sites de redes sociais. Contemporânea, v.12, n.1, 2014, p.90-106.

Coordenadora do mestrado profissional em Comunicação e Indústria Criativa e professora adjunta de Jornalismo da Universidade Federal do Pampa. Doutora em Comunicação e Informação (UFRGS). Doutora em Comunicação pela Universidade Federal do Rio Grande do Sul. Estágio de Pós-Doutorado pela Universidade Federal de Santa Maria (UFSM). Líder do GP Jornalismo em Redes e Convergência (CNPq/Unipampa).

Eugenia Mariano da Rocha Barichello Professora do Programa de Pós-Graduação em Comunicação da Universidade Federal de Santa Maria. Pós-Doutora pela University College of London (UK). Bolsista em Produtividade em Pesquisa do Conselho Nacional de Pesquisa (CNPq). Doutora em Comunicação pela Universidade Federal do Rio de Janeiro (UFRJ).

Tanise Arruda Acadêmica de Jornalismo da Universidade Federal de Santa Maria. Bolsista PDA do GP Jornalismo em Redes e Convergência. 